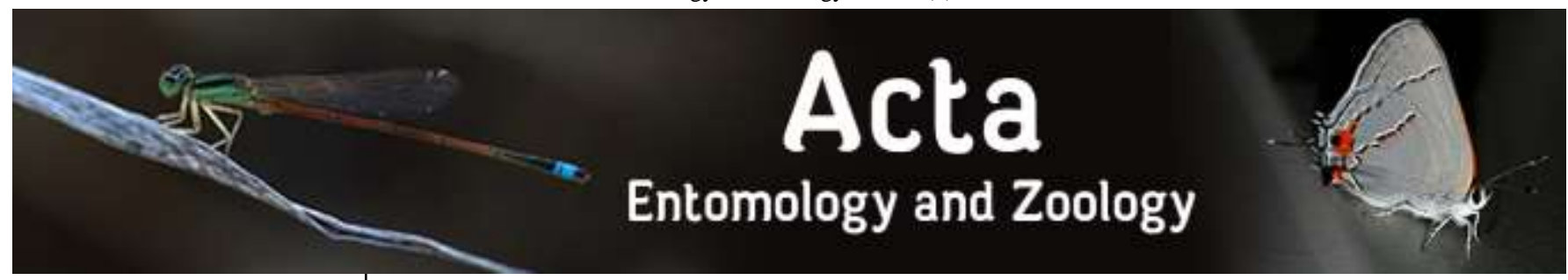

E-ISSN: 2708-0021 P-ISSN: 2708-0013 www.actajournal.com AEZ 2021; 2(1): 95-101 Received: 15-12-2020 Accepted: 23-01-202

Kari Iamba

PNG University of Natural Resources \& Environment, Private Mail Bag, Department of Agriculture, Vudal, Papua New Guinea, Australia

\section{Tonavu Yaubi}

PNG University of Natural Resources \& Environment, Private Mail Bag, Department of Agriculture, Vudal, Papua New Guinea, Australia
Corresponding Author: Kari Iamba

PNG University of Natural Resources \& Environment, Private Mail Bag, Department of Agriculture, Vudal, Papua New Guinea, Australia

\section{Incorporating lemon grass (Cymbopogon citratus $\mathbf{L}$.) and marigold (Tagetes erecta $\mathrm{L}$.) as non-host barrier plants to reduce impact of flea beetle (Chaetocnema confinis $\mathbf{C}$.) in cabbage (Brassica oleracea var. capitata L.)}

\author{
Kari Iamba and Tonavu Yaubi
}

DOI: https://doi.org/10.33545/27080013.2021.v2.i1b.33

\begin{abstract}
The repelling of insect pests and attracting of beneficial insects using non-host plants is an important component of 'push-pull' strategy. Plants with insecticidal properties are locally abundant and can be utilized to management insect pests. For this study, Lemon grass (Cymbopogon citratus L.) and Marigold plant (Tagetes erecta L.) were intercropped with cabbage (Brassica oleracea var. capitata L.) as border plants to reduce the population dynamics of flea beetle (Chaetocnema confinis C.). Lemon grass was selected based on its repellent properties while marigold for its pull mechanism. Both lemon grass and marigold were planted as barrier or border plants to cabbage. Lemon grass (C. citratus) was effective in minimizing the abundance of $C$. confinis, reduced defoliation (\%) and enhanced leaf area of cabbage plants $(p<0.05)$. Marigold $(T$. erecta) was effective in reducing the defoliation $(p<0.05)$ however it did not reduce the population of $C$. confinis and increase leaf area of cabbage. Monocrop cabbage (B. oleracea var. capitata) had the highest defoliation $(p<0.05)$ and second highest abundance of $C$. confinis $(p<0.05)$. These results shows that non-host plants can be incorporated into plant protection programs to ensure quality yield.
\end{abstract}

Keywords: 'Push-pull' strategy, lemon grass, marigold, Chaetocnema confinis, Brassica oleracea var. capitata

\section{Introduction}

Farmers in the tropics are now moving from the 'green revolution' concepts to organic farming that involves use of farm yard manure and natural pesticides. Due to adverse effects of chemicals, the public is now more aware of the negative impacts of synthetic pesticides to the beneficial insects, general human health and development of pest resistance ${ }^{[1]}$. Barrier or mixed cropping systems has been culturally practiced in many countries and their advantage on controlling pest population dynamics have proven to minimize crop damage ${ }^{[2]}$. Local farmers facing financial constraints due to high costs of pest management inputs, labour intensity and devaluation of currency can readily utilize non-host plants that have the ability to either repel pests or attract natural enemies [3, 4]. The repelling of insect pests and attracting of beneficial insects using non-host plants thus forms the basis of 'push-pull' strategy. Plants with insecticidal properties are locally abundant and can be utilized to manage insect pests ${ }^{[5]}$.

Traditional incorporation of companion plants into cropping systems is done to manage insect pests while supporting a natural enemy population through host plant diversification [6]. Companion planting or barrier planting incorporates non-host plants that can attract beneficial insects and/or repel pests ${ }^{[7,8]}$. Repellent and trap cropping systems also discourage oviposition of insect pest while boosting activities of parasitoids and predators in crops ${ }^{[9]}$. Different plant volatiles are involved in push-pull system which orchestrate pests and natural enemy populations ${ }^{[10]}$. Pests can be 'pushed' out of the crop by repellent plants, and beneficial insects can be 'pulled' by 'semiochemicals' to reduce the pests ${ }^{[11]}$.

Two (2) non-host plants, lemon grass (Cymbopogon citratus L.) and marigold plant (Tagetes erecta L.) were intercropped with cabbage (Brassica oleracea var. capitata L.) as border plants to reduce the population dynamics of flea beetle (Chaetocnema confinis $\mathrm{C}$.), reduce reduce defoliation and hence increase the leaf area. 
Due to the nutritional value and succulency of cabbage plant, it has attracted many pests species including flea beetle ( $C$. confinis) ${ }^{[12-14]}$. Flea beetles are attracted to the glucosinolate presence in cabbage plants and cause foliar damage to cabbage plants in tropical regions ${ }^{[15,16]}$. Previous studies have shown that both lemon grass ( $C$. citratus) and marigold plant (T. erecta) can lower pest infestation in crops $[1,17]$.

\section{Materials and Methods}

\section{(a) Study site}

The study was done at the academic crops section at PNG University of Natural Resources and Environment (PNG UNRE) campus in East New Britain, Papua New Guinea (PNG). The academic crops section is a regular experimental site for research studies which are done throughout the academic year. PNG UNRE is an Agricultural and Environmental institution that focuses its research programs in natural resource management such as Agriculture, Fisheries, Forestry and Animal Sciences. It is situated at an elevation of 51 meters above sea level at approximately $4^{\circ} 21^{\prime} 01.90 " \mathrm{~S}$ and $152^{\circ} 5400^{\prime} 33.44^{\prime \prime} \mathrm{E}^{[18 \text {, }}$ ${ }^{19]}$. The soil has been categorized as more calcareous in nature and relatively sandy loamy of high alkalinity ${ }^{[20]}$. The climate is classified as tropical with a great deal of rainfall experienced all year round even in the driest month.

\section{(b) Nursery}

Prior to the experiment, a nursery was established by sowing cabbage seeds in nursery trays at the nursery house at academic crops section. A total of 280 seeds were sown to cater for all the experimental plots. Cabbage seedlings were grown for three (3) weeks in the nursery house to ensure hardening before transplanting. Hardening process was done to acclimatized the seedlings to the field weather conditions. This will help the seedlings to withstand the harsh weather conditions when transplanted into field experimental plots.

\section{(c) Experimental design}

Site clearance began after the sowing of seeds in the nursery. The experimental site was cleared, soil dug manually to loosen soil particles and to unwanted weeds removed. Proper drainages were done to remove excessive water and prevent any possibility of waterlog conditions. After that, the land was divided into experimental plots according to the Complete Randomized Block design (CRBD). Each plot measured $2 \times 2 \mathrm{~m}\left(4 \mathrm{~m}^{2}\right)$ with a spacing of $40 \mathrm{~cm}$ between plants and $50 \mathrm{~cm}$ between rows. Therefore, each plot had a plant density of 20 plants per plot $\left[\left(4 \mathrm{~m}^{2}\right.\right.$ / $\left.\left(\begin{array}{lll}0.4 & \mathrm{x} & 0.5\end{array}\right)\right]$. There were three treatments applied: (1) $\mathrm{T} 1=$ lemon grass + cabbage, (2) $\mathrm{T} 2=$ marigold plant + cabbage, and $\mathrm{T} 3=$ monocrop cabbage (control) with each treatment replicated three times. Lemon grass was selected based on its repellent properties while marigold for its pull mechanism. Both lemon grass and marigold were planted as barrier or border plants to cabbage plants. The non-host plants were also grown 3 months prior to transplanting in the nursery to ensure they reach vegetative stage. They were transplanted 2 weeks prior to transfer of seedlings to the field plots. During the experimental phase, there was no insecticide or pesticide used nor any chemical fertilizers because the objective was to test the effect of the non-host plants. At 21-30 days after seeding (DAS), cabbage seedlings were transplanted to the field plots following the recommendation of 1 seedling per hole at shallow depth.

\section{(d) Sampling and data collection}

Three response variables were measured to calculate the impact of cabbage flea beetle under each treatment. The abundance was basically the number of flea beetles counted during each sampling time. Since flea beetles are very mobile, they were observed with less disturbance to foliar. Both the defoliation (\%) and leaf area index (LAI) were calculated using an application called the BioLeaf Foliar Analysis in an android phone, A sample of leaf was placed against a white paper, a clear shot was taken using the phone camera (13-megapixel), and the app itself did all the scanning and calculated the defoliation (\%) and LAI. Sampling was done randomly at all growth stages involving the seedling ( 2 weeks after transplanting), crowning (5-6 weeks after transplanting) and harvesting phase (11-13 weeks after transplanting). Actually, data was collected once per week for a total period of 5-weeks. The abundance, defoliation and LAI of 5 cabbage plants per treatment plot were recorded per week. So, in total, there were 15 data collected per treatment per replicate multiplied by 3 treatments and 3 replicates $(15 \times 3 \times 3)$ which gave a total of 135 data per sampling per week. Since the sampling took 5 weeks, the grand total of collected data was 675 (5x135).

\section{(e) Data analysis}

All data were analysed using the Generalized Linear Model (GzLM) with Gamma exponential family and log link function in RStudio (version 4.0.3). Simple ANOVA and linear modelling were dim unsuitable since the data pertaining to the response variables were not normally distributed according to Shapiro-Wilk test $(p<0.05)$. The Akaike's information criterion (AIC) in Gamma GzLM was lower than the Poisson family across all tested variables therefore it was chosen as a suitable model for the data analysis ${ }^{[21]}$. Graphs relating to abundance, defoliation and LAI were constructed with ggplot 2 package. Tukey Honest Significant Difference test (Tukey HSD) was used to separate means of each treatment and sampling week. Cross-factor analyses was also done to test the interaction of treatments and growth stage (week) on abundance, defoliation and LAI. For graphical presentation of the factor analyses, a combination of ggplot 2 and cowplot package were executed in RStudio.

\section{Results}

A total of 675 plants were sampled during the study with 654 data points for $C$. confinis abundance, 1238.09 for defoliation (\%) and 749.51 for leaf area index (LAI). The aim was to test the efficacy of border non-host plants against the impact of $C$. confinis on cabbage (B. oleracea var. capitata). The treatments; (1) Lemon grass+cabbage, (2) Marigold+cabbage and (3) Control (sole cabbage), had varying tendency to protect cabbage plants from $C$. confinis. The weekly sampling (growth stages) was also considered a factor influencing the response variables. From the data, Lemon grass $(C$. citratus) was effective in controlling the impact of $C$. confinis than marigold ( $T$. erecta) and monocrop cabbage (B. oleracea var. capitata). The abundance of $C$. confinis under lemon grass treatment significantly reached its lowest at week $2(2.08 \pm 0.29$, $\sigma=0.99, p<0.05)$. The highest abundance under lemon grass was recorded in week 3 which was statistically significant $(3.36 \pm 0.59, \sigma=1.96, p<0.05)$ (table 1$)$. 
Table 1: Three treatments tested against Flea beetle (Chaetocnema confinis C.) were Lemon grass (Cymbopogon citratus L.), Marigold flower (Tagetes erecta L.) and monocrop cabbage (Brassica oleracea var. capitata L.). The measurements from different response variables: (1) abundance, (2) defoliation (\%) and, (3) leaf area index (LAI) is given in this table.

\begin{tabular}{|c|c|c|c|c|}
\hline *Sampling & ${ }^{*}$ Treatments & $\begin{array}{c}\text { Abundance } \\
\text { mean } \pm \mathrm{SE}^{\mathrm{HSD}}(\mathrm{SD})\end{array}$ & $\begin{array}{c}\text { Defoliation (\%) } \\
\text { mean } \pm \mathrm{SE}^{\mathrm{HSD}}(\mathrm{SD})\end{array}$ & $\begin{array}{c}\text { LAI } \\
\operatorname{mean} \pm \mathrm{SE}^{\mathrm{HSD}}(\mathrm{SD})\end{array}$ \\
\hline Week 1 & $\begin{array}{l}\text { Lemon grass } \\
\text { Marigold } \\
\text { Monocrop }\end{array}$ & $\begin{array}{c}2.64 \pm 0.65^{\text {efg }}(2.16) \\
3.00 \pm 0.67^{\operatorname{defg}}(2.11) \\
2.11 \pm 0.35^{\mathrm{g}}(1.05)\end{array}$ & $\begin{array}{c}1.40 \pm 0.35^{\mathrm{e}}(1.15) \\
3.89 \pm 1.11^{\text {bc }}(3.52) \\
1.44 \pm 0.35^{\mathrm{e}}(1.04)\end{array}$ & $\begin{array}{c}7.26 \pm 0.75^{\mathrm{a}}(2.49) \\
5.29 \pm 0.71^{\text {cde }}(2.26) \\
7.53 \pm 0.67^{\mathrm{a}}(2.02)\end{array}$ \\
\hline Week 2 & $\begin{array}{c}\text { Lemon grass } \\
\text { Marigold } \\
\text { Monocrop }\end{array}$ & $\begin{array}{l}2.08 \pm 0.29^{\mathrm{g}}(0.99) \\
3.71 \pm 0.38^{\mathrm{cd}}(1.44) \\
2.36 \pm 0.36^{\text {fg }}(1.21)\end{array}$ & $\begin{array}{c}3.15 \pm 0.99^{\mathrm{cd}}(3.41) \\
6.13 \pm 1.12^{\mathrm{a}}(4.19) \\
4.42 \pm 0.99^{\mathrm{b}}(3.28)\end{array}$ & $\begin{array}{c}5.99 \pm 0.62^{\mathrm{b}}(2.15) \\
4.47 \pm 0.52^{\mathrm{f}}(1.95) \\
5.39 \pm 0.54^{\text {cde }}(1.77)\end{array}$ \\
\hline Week 3 & $\begin{array}{c}\text { Lemon grass } \\
\text { Marigold } \\
\text { Monocrop } \\
\end{array}$ & $\begin{array}{l}3.36 \pm 0.59^{\text {cde }}(1.96) \\
3.79 \pm 0.72^{\text {cd }}(2.69) \\
4.07 \pm 0.61^{\text {bc }}(2.27) \\
\end{array}$ & $\begin{array}{c}2.78 \pm 0.60^{\mathrm{cd}}(1.99) \\
3.22 \pm 0.60^{\mathrm{cd}}(2.25) \\
6.87 \pm 1.20^{\mathrm{a}}(4.51)\end{array}$ & $\begin{array}{l}5.45 \pm 0.45^{\mathrm{cd}}(1.50) \\
5.15 \pm 0.36^{\mathrm{de}}(1.33) \\
3.72 \pm 0.41^{\mathrm{g}}(1.53) \\
\end{array}$ \\
\hline Week 4 & $\begin{array}{l}\text { Lemon grass } \\
\text { Marigold } \\
\text { Monocrop }\end{array}$ & $\begin{array}{c}3.07 \pm 0.55^{\mathrm{def}}(2.12) \\
5.21 \pm 0.88^{\mathrm{a}}(3.31) \\
3.25 \pm 0.51^{\text {cdef }}(1.76)\end{array}$ & $\begin{array}{l}3.09 \pm 0.47^{\mathrm{cd}}(1.82) \\
2.64 \pm 0.41^{\mathrm{d}}(1.52) \\
3.79 \pm 0.72^{\text {bc }}(2.49)\end{array}$ & $\begin{array}{l}5.06 \pm 0.39^{\mathrm{de}}(1.54) \\
5.45 \pm 0.45^{\mathrm{cd}}(1.67) \\
4.95 \pm 0.50^{\mathrm{e}}(1.73)\end{array}$ \\
\hline Week 5 & $\begin{array}{l}\text { Lemon grass } \\
\text { Marigold } \\
\text { Monocrop }\end{array}$ & $\begin{array}{l}2.79 \pm 0.43^{\mathrm{efg}}(1.63) \\
4.71 \pm 0.90^{\mathrm{ab}}(3.38) \\
3.67 \pm 0.74^{\mathrm{cd}}(2.87)\end{array}$ & $\begin{array}{c}2.64 \pm 0.38^{\mathrm{d}}(1.41) \\
2.83 \pm 0.39^{\mathrm{cd}}(1.47) \\
3.52 \pm 0.50^{\mathrm{bcd}}(1.94)\end{array}$ & $\begin{array}{c}5.61 \pm 0.44^{\text {bc }}(1.66) \\
5.23 \pm 0.27^{\text {cde }}(1.00) \\
4.98 \pm 0.32^{\mathrm{e}}(1.25)\end{array}$ \\
\hline
\end{tabular}

${ }^{*}$ The groups are grouped according to probability of means differences and alpha level (0.05).

${ }^{\dagger}$ Treatments with the same letter are not significantly different with SD for the standard deviation $(\sigma)$. All separation of means is produced by Tukey Honest Significant Difference (HSD)

Marigold ( $T$. erecta) treatment recorded the highest significant abundance at week $4(5.21 \pm 0.88, \sigma=3.31$, $p<0.05)$ while the lowest in week $1(3.00 \pm 0.67, \sigma=2.11$, $p<0.05)$. Control treatment (monocrop), had the highest abundance in week $3(4.07 \pm 0.61, \sigma=2.27, p<0.05)$ and lowest in week $1(2.11 \pm 0.35, \sigma=1.05, p<0.05)$ which were statistically significant (table 1). The highest defoliation under lemon grass treatment was detected at week 2 $(3.15 \pm 0.99,3.41, p>0.05)$ and the lowest at week 1 $(1.40 \pm 0.35, \sigma=1.15, p<0.05)$ which was significant. Marigold had the highest defoliation at week $2(6.13 \pm 1.12$, $\sigma=4.19, p<0.05)$ and lowest at week $4(2.64 \pm 0.41, \sigma=1.52$, $p<0.05)$ which were all significant. The peak defoliation in monocrop cabbage was at week $3(6.87 \pm 1.20, \sigma=4.51$, $p<0.05)$ and lowest at week $1(1.44 \pm 0.35, \sigma=1.04, p<0.05)$. Lemon grass had the highest significant leaf area index (LAI) at week $1(7.26 \pm 0.75, \sigma=2.49, p<0.05)$ and lowest at week $4(5.06 \pm 0.39, \sigma=1.54, p<0.05)$. The highest LAI under marigold treatment was at week $4(5.45 \pm 0.45, \sigma$ $=1.67, p<0.05)$ and lowest recorded at week $2(4.47 \pm 0.52, \sigma$ $=1.95, \mathrm{p}<0.05$ ). Monocrop (sole cabbage) recorded the highest LAI at week $1(7.53 \pm 0.67, \sigma=2.02, p<0.05)$ and lowest at week $3(3.72 \pm 0.41, \sigma=1.53, p<0.05)$ (table 1$)$.

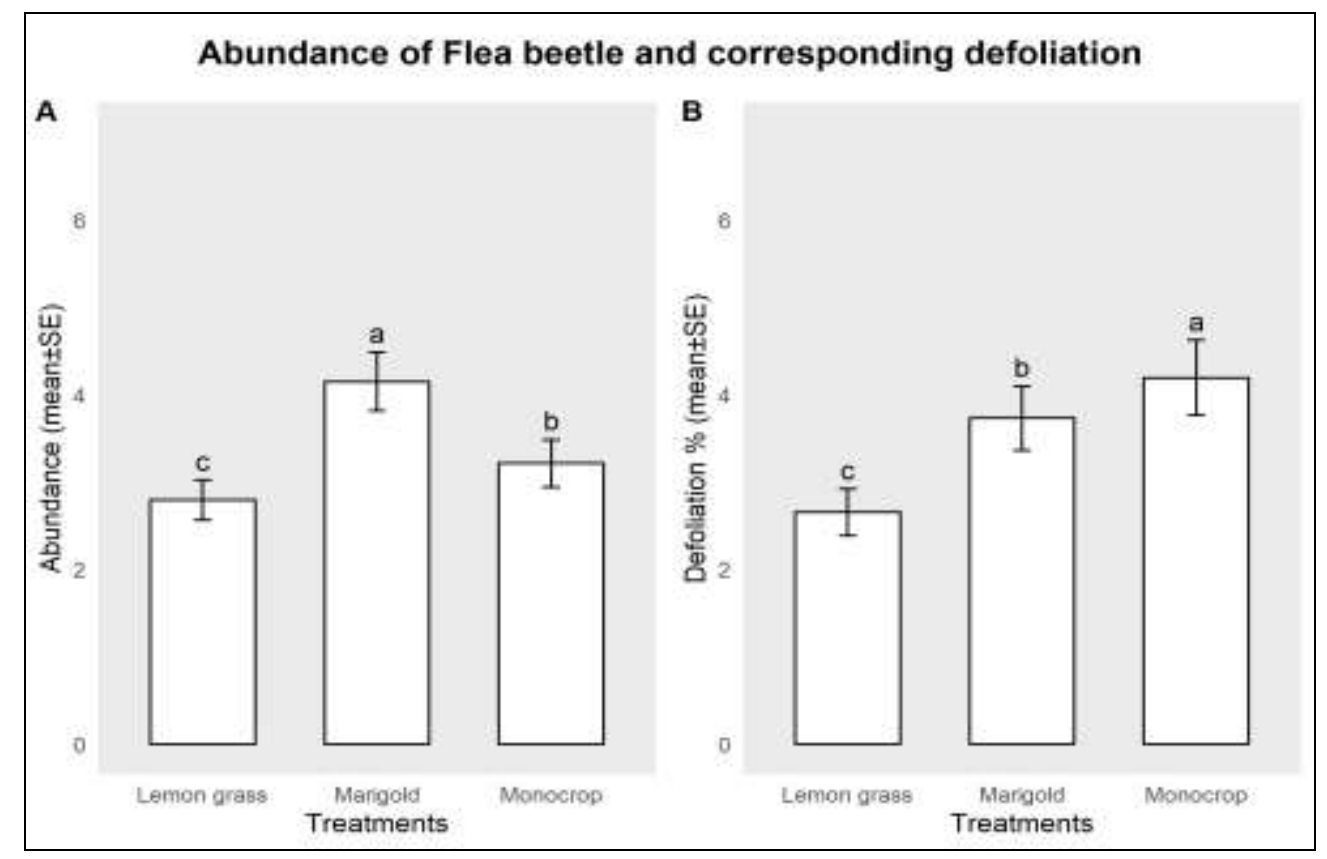

Fig 1: Two sets of graphs showing the abundance (A) and defoliation (B) under the three treatments. The lemon grass and marigold flowers were planted as border plants around the plots to protect cabbages from Flea beetle attack. The monocrop treatment (control) did not have any border plants. Marigold had the highest pest abundance $(\mathrm{p} \leq 0.05)$ while lemon grass recorded significantly low defoliation ( $\mathrm{p} \leq 0.05)$. Treatments with the same letter are not significantly different.

The abundance (mean $\pm \mathrm{SE}$ ) of $C$. confinis was statistically significant under marigold treatment which had the highest abundance (4.15 $\pm 0.34, \sigma=2.75, p<0.05)$ (fig. 1). Control (monocrop) treatment had the second highest abundance $(3.21 \pm 0.27, \sigma=2.13, p<0.05)$ while lemon grass treatment had the lowest $C$. confinis abundance $(2.79 \pm 0.23, \sigma=1.82$, 
$p<0.05)$. Corresponding defoliation (\%) was significantly lowest in lemon grass treatment $(2.65 \pm 0.27, \sigma=2.11$, $p<0.05)$. There was also significant defoliation in marigold $(3.73 \pm 0.37, \quad \sigma=2.98, \quad p<0.05)$ whereas the highest

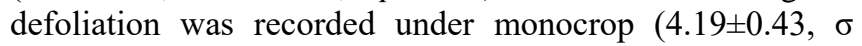

$=3.36, p<0.05$ ) treatment (fig. 1). Plots incorporating lemon grass as border rows were able to reduce defoliation significantly than marigold and control plots. Lemon grass plots had low abundance of $C$. confinis and corresponding low defoliation in cabbage plants.

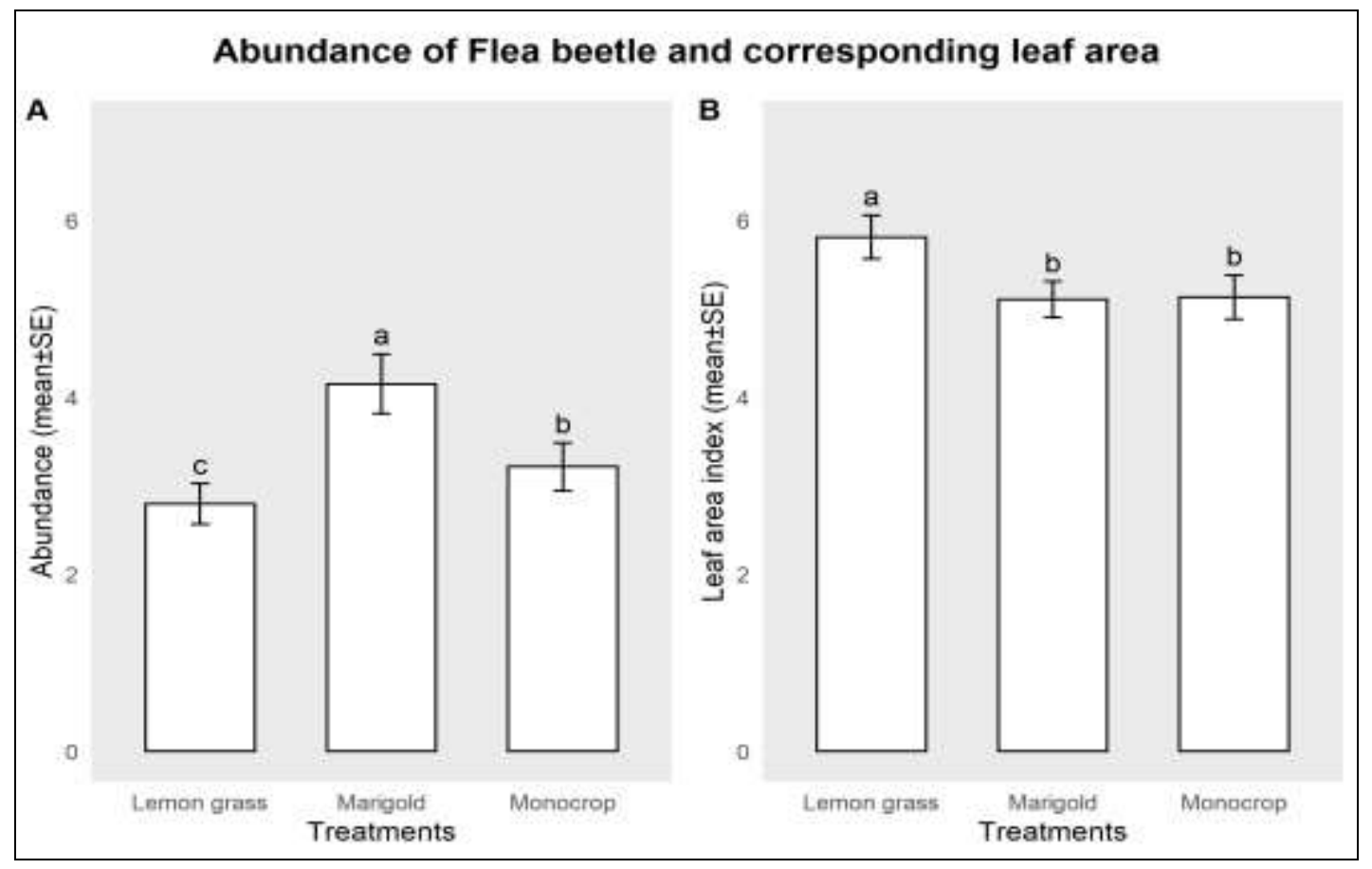

Fig 2: The two graphs show the abundance (A) and leaf area index (B) under the three treatments. Marigold had significantly high pest abundance $(\mathrm{p} \leq 0.05)$ while lemon grass recorded a significant increase in LAI $(\mathrm{p} \leq 0.05)$. Treatments with the same letter are not significantly different.

The abundance (mean $\pm \mathrm{SE}$ ) of $C$. confinis was statistically significant under marigold treatment as shown in figure 1 and 2. Abundances of both lemon grass and control treatments were also statistically significant (fig.1). Corresponding leaf area index (LAI) was significantly higher in lemon grass treatment $(5.81 \pm 0.25, \sigma=1.96$, $p<0.05$ ) (fig. 2). However, there were no significant differences in LAI between marigold $(5.12 \pm 0.20, \sigma=1.64$, $p>0.05)$ and monocrop $(5.13 \pm 0.25, \sigma=1.96, p>0.05)$ treatments (fig. 2). Plots incorporating lemon grass were able to increase leaf area of cabbage plants than marigold and control plots. Lemon grass plots had lower abundance of $C$. confinis while producing bigger leaf areas (fig. 2).

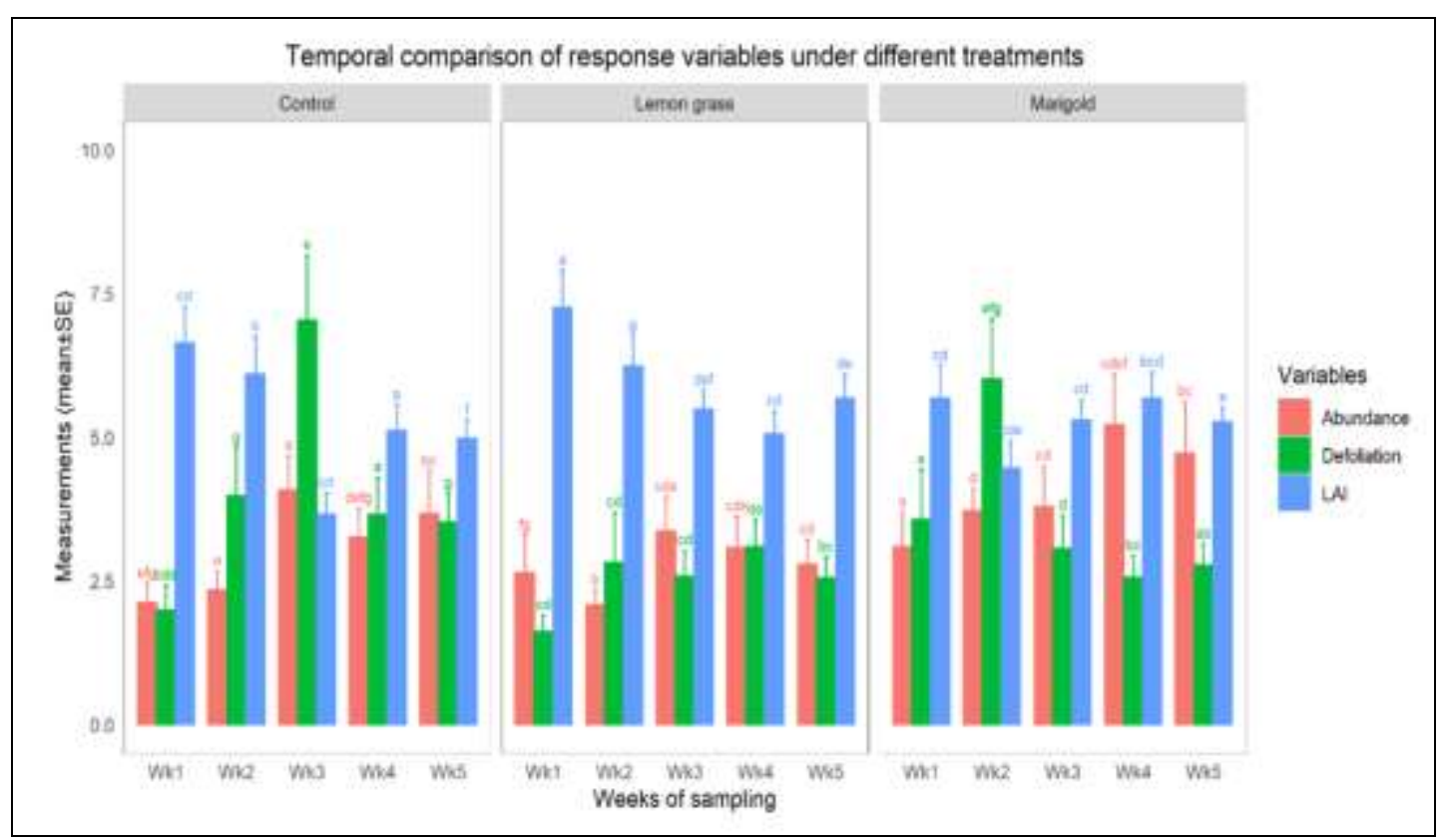

Fig 3: The three response variables; (1) abundance, (2) defoliation and (3) LAI fluctuated in relation to sampling weeks. The sampling weeks are representing the weekly growth stages of cabbages. There is distinct variable trajectory under the three treatments; (a) control (monocrop), (b) lemon grass, and (c) marigold. Variables with the same letter are not significantly different. 
The abundance of $C$. confinis were non-significantly lower in week 1 and week $2(p>0.05)$ under control treatment but reached its highest in week $3(p<0.05)$ (fig. 3). Subsequent population at week 4 and week 5 did not differ significantly. Defoliation was significantly lower in week $1 \quad(p<0.05)$ under control treatment but reached its highest in week 3 $(p<0.05)$. There was a significant drop in week 4 and week $5(\mathrm{p} \leq 0.05)$. LAI was highest at week $1 \quad(p<0.05)$, but gradually decreased significantly from week 3 to week 5 $(p<0.05)$.

The abundance of $C$. confinis in week 1 under lemon grass treatment was higher than week $2(p<0.05)$ however there was no significant difference in week 3 , week 4 and week 5 $(p<0.05)$ (fig. 3). Defoliation did not differ significantly in week 1 , week 2 and week $3(p>0.05)$ under lemon grass treatment however there was slight increase in week 4 and a drop in week $5(p<0.05)$. LAI subsequently decreased from week 1 to week 4 ( $p<0.05)$. The LAI increased in week 5 but did not significantly differ from week $3(p>0.05)$.

The abundance of $C$. confinis was significantly lower in week $1 \quad(p<0.05)$ under marigold treatment but did not significantly differ between week 2 and week $3(p>0.05)$ (fig. 3). The highest abundance was recorded in week 4 $(p<0.05)$ while dropping in week $5(p<0.05)$. Defoliation in week 1 under marigold treatment was significantly higher than week 3 , week 4 and week $5(p<0.05)$, however, the highest defoliation was recorded at week $2(p<0.05)$. The highest LAI were recorded in week 1 and week $4(p>0.05)$ while week 2 had the lowest LAI $(p<0.05)$.

\section{Discussion}

The incorporation of non-host plants in organic farming plays an important role of push-pull mechanism to manage insect pests. Non-host plants can either repel pests from crops or attract natural enemies to control pests. By looking at the results, it is evident that lemon grass ( $C$. citratus) provided better border protection to cabbage plants than marigold flower (T. erecta) and monocrop cabbage. Border cropping of lemon balm greatly reduced the density of striped flea beetle in Chinese cabbage plots and therefore was recommended as a preventive control for striped flea beetle under organic farming system ${ }^{[22]}$. Insects that are exposed to volatile natural compounds can develop physiological changes in their reproductive system and pherohormone perception leading to abnormal ovipositional ability ${ }^{[23]}$. Chemical volatiles from lemon grass (C. citratus) were able to repel the cabbage flea beetle ( $C$. confinis) thus reducing defoliation and maintaining higher leaf area (LAI). The volatile aromatic compound (VACs) present in lemon grass oil are myrcene, $\alpha$-thujene, cis- $\beta$-ocimene, trans- $\beta$ ocimene, citronellal, limonene oxide, citronellol, cis-citral, trans-citral, geraniol, $\alpha$-copaene, and humulene ${ }^{[24]}$. Chanthai, Prachakoll ${ }^{[24]}$ also reported that a chemical constituent known as eugenol often functions as attractant was not detected in lemon grass (C. citratus) but was present in citronella grass $(C$. nardus). A study on lemon grass $(C$. citratus) identified the chemicals geranial and neral as active components in repelling Culex pipiens pallens ${ }^{[25]}$. These active ingredients; $\alpha$-Pinene, $\beta$-pinene, eucalyptol, carveol and D-carvone in lemon grass oil attracted the female egg parasitoid, Anagrus nilaparvatae which suggested that plant essential oils could serve as attractants for natural enemies to control pests ${ }^{[26]}$. Lemon grass significantly reduced the passage of sweet potato weevil (Cylas formicarius) in sweet potato ${ }^{[27]}$. In a toxicity test, adult mortality of rice weevil, Sitophilus oryzae, increased as concentrations of $C$. citratus extract increased from $1.0-2.5 \mathrm{~g}$ in $24-96 \mathrm{~h}{ }^{[28]}$. An experiment showed that $2 \%$ lemon grass oil was able to inhibit Spodoptera exigua moths from laying eggs on Nerium leaves ${ }^{[29]}$. Lemon grass also reduced insect pest attack when it was intercropped with the main crop ${ }^{[17]}$.

Marigold treatment had the highest abundance of cabbage flea beetle (C. confinis) which can be attributed to its pull strategy role ${ }^{[1]}$. However, the defoliation in marigold treatment was significantly lower than control plot while having similar LAI as control treatment. Population of flea beetle and defoliation in cabbage was significantly lower in marigold intercrop plots than in sole cabbage plots ${ }^{[30]}$. Unlike lemon grass, marigold utilizes the pull strategy by attracting both pests and natural enemies ${ }^{[9]}$. Volatile chemicals produced by marigold $(T$. erecta) cotains benzaldehyde, linalool, myroxide, piperitone, limonene, ocimene, lagetone and valeric acid which attracts both the pests and natural enemies [31, 32]. Marigold has been recognized as an important plant that maintains a high natural enemy biodiversity ${ }^{[33-35]}$.

According to Andaloro, Rose [36], cabbage generally has nine (9) stages of growth: stage 1 (cotyledon), stage 2 (seedling), stage 3 (6-8 true leaf), stage 4 (9-12 true leaf), stage 5 (precupping), stage 6 (cupping), stage 7 (early head formation), stage 8 (head fill) and stage 9 (mature). Cabbage flea beetle mainly attacks stage 1 and stage 2 while less important in stage 3 as the foliage gets larger ${ }^{[36]}$. Week 3 of control treatment (monocrop cabbage) represented the end of stage 2 and beginning of stage 3 where the cabbage plants were most succulent (fig. 3). In week 4 and week 5, cabbage plants were into cupping stages with larger leaves therefore defoliation and decrease in LAI can be attributed to other prevalent pest species such as diamondback moth (Plutella xylostella) and fall army worm (Spodoptera frugiperda).

\section{Conclusion}

The two non-host plants, lemon grass (C. citratus) and marigold plant ( $T$. erecta) that were tested as border plants provided promising results on cabbage (B. oleracea var. capitata). Lemon grass significantly minimized the population abundance of flea beetle ( $C$. confinis), reduced defoliation and enhanced the leaf area of cabbage plants. Marigold provided medium protection to cabbage in terms of reduced defoliation however its contribution to lower abundance and increase LAI were non-significant. This study thereby recommends future experiments to test the efficacy of these two non-host plants on other cabbage pests as well. Based on previous studies, both lemon grass $(C$. citratus) and marigold plant (T. erecta) can lower pest infestation in crops ${ }^{[1,17]}$.

\section{Acknowledgments}

We are grateful for the technical and logistical support of technical officers at Academic crops section. Special thanks to Mrs Lina Iamba for her moral support, patience and encouragement that led to the successful completion of the manuscript. We extend our appreciation to the academic staffs of PNG UNRE who have been supporting our research initiatives. 


\section{References}

1. Iamba K, Homband V. Intercropping of Pak choi (Brassica rapa chinensis) with Marigold flower (Tagetes erecta L.) and Onion (Allium cepa L.) to control foliar pests. Journal of Entomology and Zoology Studies 2020;8(6):731-737.

2. Perrin R, Phillips M. Some effects of mixed cropping on the population dynamics of insect pests. Entomologia Experimentalis et Applicata 1978;24(3):585-593.

3. Sonwa DJ et al., Integrated pest management in cocoa agroforests in southern Cameroon: Constraints and overview. Integrated Pest Management Reviews 2002;7(3):191-199.

4. Coulibaly $\mathrm{O}$ et al., Responding to economic crisis in sub-Saharan Africa: New farmer-developed pest management strategies in cocoa-based plantations in Southern Cameroon. Integrated Pest Management Reviews 2002;7(3):165-172.

5. Iamba K, Masu H. An integrated approach of managing Conopomorpha cramerella Snellen: Application of plant extracts in a push-pull system. Journal of Entomology and Zoology Studies 2020;8(6):10401046.

6. Sarkar SC et al., Application of trap cropping as companion plants for the management of agricultural pests: a review. Insects 2018;9(4):128.

7. Hokkanen HT. Trap cropping in pest management. Annual Review of Entomology 1991;36:119-138.

8. Shelton A, Badenes-Perez F. Concepts and applications of trap cropping in pest management. Annu. Rev. Entomol 2006;51:285-308.

9. Liu SS, Li YH, Lou YG. Non-host plant extracts reduce oviposition of Plutella xylostella (Lepidoptera: Plutellidae) and enhance parasitism by its parasitoid Cotesia plutellae (Hymenoptera: Braconidae). Bulletin of Entomological Research 2007;96(4):373-378.

10. Bhattacharyya $M$. The push-pull strategy: A new approach to the eco-friendly method of pest management in agriculture. Journal of Entomology and Zoology Studies 2017;5(3):604-607.

11. Khan $\mathrm{Z}$ et al., Push-pull: chemical ecology-based integrated pest management technology. Journal of chemical ecology 2016;42(7):689-697.

12. Chalfant $\mathrm{R}$ et al., Management of Cabbage Caterpillars in Florida and Georgia by Using Visual Damage Thresbolds. Journal of Economic Entomology 1979;72(3):411-413.

13. Shelton A, Andaloro J, Barnards J. Effects of cabbage looper, imported cabbageworm, and diamondback moth on fresh market and processing cabbage. Journal of Economic Entomology 1982;75(4):742-745.

14. Mochiah MP, Baidoo, Owusu-Akyaw M. Influence of different nutrient applications on insect populations and damage to cabbage 2011.

15. De Lannoy G. Vegetables: Crop production in Tropical Africa. Directorate General for Intl. Cooperation, Brussels, Belgium 2001, 403-511.

16. Bartlet E, Williams I. Factors restricting the feeding of the cabbage stem flea beetle (Psylliodes chrysocephala). Entomologia experimentalis et applicata 1991;60(3):233-238.

17. Ebuenga dM, Gonzales PG. Impact of intercropping lemon grass (Cymbopogon citratus Stapf.) on infestation of eggplant fruit and shoot borer (Leucinodes orbonalis Guenee) in eggplant (Solanum melongena L.). Margaret Helen Udarbe-Alvarez, Ph. D., Editor 2013;54(1):114.

18. Iamba K, Yoba S. Compatibility of Predators and Botanical Extracts against Plutella xylostella on round cabbage. IOSR Journal of Agriculture and Veterinary Science (IOSR-JAVS) 2019;12(11):64-68.

19. Iamba K, Yoba S. Spatio-temporal dispersion patterns of Bactrocera musae Tryon (Diptera: Tephritidae: Dacinae) in Vudal agroecosystem, East New Britain. International Journal of Entomology Research 2020;5(6):78-84.

20. Iamba K, Malapa S. Efficacy of selected plant extracts against diamondback moth (Plutella xylostella L.) on round cabbage in situ. Journal of Entomology and Zoology Studies 2020;8(1):1240-1247.

21. Royer JE, Tan KH, Mayer DG. Comparative Trap Catches of Male Bactrocera, Dacus, and Zeugodacus Fruit Flies (Diptera: Tephritidae) With Four Floral Phenylbutanoid Lures (Anisyl Acetone, Cue-Lure, Raspberry Ketone, and Zingerone) in Queensland, Australia. Environmental Entomology 2020.

22. Han EJ et al., Suppressive Effect of Repellent Plant Cultivation against Striped Flea Beetle of Chinese Cabbage. Korean Journal of Organic Agriculture, 2015;23(4):911-921.

23. Guarino $\mathrm{S}$ et al., Behaviour-modifying compounds for management of the red palm weevil (Rhynchophorus ferrugineus Oliver). Pest management science 2015;71(12):1605-1610.

24. Chanthai S et al., Influence of extraction methodologies on the analysis of five major volatile aromatic compounds of citronella grass (Cymbopogon nardus) and lemongrass (Cymbopogon citratus) grown in Thailand. Journal of AOAC International 2012;95(3):763-772.

25. Leal WS, Uchida K. Application of GC-EAD to the determination of mosquito repellents derived from a plant, Cymbopogon citratus. Journal of Asia-Pacific Entomology 1998;1(2):217-221.

26. Mao GF et al., Attraction behaviour of Anagrus nilaparvatae to remote lemongrass (Cymbopogon distans) oil and its volatile compounds. Natural product research 2018;32(5):514-520.

27. Dada TE et al., Screening barrier plants to reduce crop attack by sweet potato weevil (Cylas formicarius). Pest management science 2020;76(3):894-900.

28. Uwamose MO et al., Toxicity of lemon grass Cymbopogon citratus powder and methanol extract against rice weevil Sitophilus oryzae (Coleoptera: Curculionidae). Journal of Coastal Life Medicine, 2017;5(3):99-103.

29. Sharaby A. Anti-insect properties of the essential oil of lemon grass, Cymbopogen citratus against the lesser cotton leafworm Spodoptera exigua (Hbn). International Journal of Tropical Insect Science 1988;9(1):77-80.

30. Latheef M, Ortiz J, Sheikh A. Influence of intercropping on Phyllotreta cruciferae (Coleoptera: Chrysomelidae) populations on collard plants. Journal of economic entomology 1984;77(5):1180-1184.

31. Burguiere L, Marion-Poll F, Cork A. Electrophysiological responses of female Helicoverpa 
armigera (Hübner) (Lepidoptera; Noctuidae) to synthetic host odours. Journal of Insect Physiology, 2001;47(4, 5):509-514.

32. Meshkatalsadat $\mathrm{MH}$ et al., Chemical characterization of volatile components of Tagetes minuta L. Cultivated in south west of Iran by nano scale injection. Digest Journal of nanomaterials and Biostructures 2010;5(1):101-106.

33. Silveira LCP et al., Marigold (Tagetes erecta L.) as an attractive crop to natural enemies in onion fields. Scientia agricola 2009;66(6):780-787.

34. Silveira LCP, Bueno VHP, Mendes SM. Record of two species of Orius Wolff (Hemiptera, Anthocoridae) in Brazil. Revista Brasileira de Entomologia 2003;47(2):p. 303-306.

35. Silveira L, Bueno VP, Van Lenteren J. Orius insidiosus as biological control agent of thrips in greenhouse chrysanthemums in the tropics. Bulletin of Insectology, 2004;57(2):103-109.

36. Andaloro J et al., Cabbage growth stages [Susceptibility to pests and diseases]. New York's Food and Life Sciences Bulletin (USA) 1983, 101. 